\title{
Lengua e Historia. La contribución de la lingüística al conocimiento de las épocas anteriores a la Reconquista en Alcalá de Guadaira
}

\author{
María Dolores Gordón Peral
}

Una fuente de información histórica muy particular y extremadamente elocuente, pero paradójicamente poco estudiada en nuestra región y aun menos conocida por los historiadores, la constituyen los nombres de lugar. Si el análisis toponomástico es una labor primordialmente lingüística -que, en consecuencia, ha de ser llevada a cabo por expertos en tal materia-, para la interpretación extralingüística de los datos extraídos del estudio léxico-semántico de los nombres, no obstante, es sumamente fructífera la colaboración y el asesoramiento de parte de los historiadores y arqueólogos.

El sector de la investigación histórica donde más valor cobra el testimonio de los nombres de lugar probablemente es el de las épocas tempranas, para cuyo conocimiento carecemos casi completamente de documentación escrita; esta falta de datos explícitos puede ser cubierta en cierta medida por la investigación arqueológica, y, como complemento de ésta, por el estudio lingüístico de dos tipos de nombres de lugar muy peculiares:

a) los que remontan a estratos lingüísticos anteriores al vigente en la actualidad;

b) los impuestos en el estrato vigente hoy día, pero basados en léxico que hace alusión a la existencia, en los sitios denominados, de restos de interés arqueológico.

Tales tipos de nombres de lugar aparecen en todas las zonas que han estado pobladas desde antiguo. Y, por ello, naturalmente, hallamos numerosos representantes tanto del grupo a) como del b) también en el área del término municipal de Alcalá de Guadaira, habitado, según han mostrado hallazgos arqueológicos, desde época prehistórica. Veamos, pues, cuáles son estos topónimos alcalareños tan elocuentes acerca del pasado de la zona, y las conclusiones que pueden ser extraídas del hecho de su existencia. 


\section{A. Topónimos precastellanos}

Sabido es que los topónimos, por oscuros e indescifrables que resulten para el hablante actual, fueron en un principio, en la época de su creación, elementos vivos, apelativos, voces comunes de la lengua hablada, y que por tanto tenían un significado bien claro para sus creadores. Para los objetivos que perseguimos ahora no nos interesa tanto el significado que tenía el léxico en que se basan los nombres (que, por lo demás, puede ser muy interesante para reconstruir la historia de cada lugar concreto), como la adscripción de cada forma a uno u otro estrato histórico-lingüístico vigente en alguna época de la historia de Alcalá de Guadaira y su conservación a través de dos o más estratos. La pervivencia hasta hoy de un nombre precastellano es indicio seguro de que el lugar nombrado ha estado poblado sin solución de continuidad al menos desde la época de la vigencia del estrato al que pertenece ${ }^{1}$.

1. El estrato histórico-lingüístico más copiosamente representado en la toponimia de la zona de Alcalá es el inmediatamente precedente al vigente en la actualidad, a saber, el árabe. Remontan a esta capa los siguientes nombres de lugar:

- Alcalá: del árabe al-qalat 'el castillo, la fortaleza';

-Sahela: de unhispanoárabe *as-Sahel, forma dialectal de al-sahl 'elllano'; nombre de un distrito de la cora de Sevilla ${ }^{2}$.

- Marchamorón (documentado machar almorirí en el siglo XIII); contiene el hispanoárabe maŷšar 'cortijo' y un gentilicio ‘de Morón' ${ }^{3}$.

-Realaje: nombre de un molino de la ribera del Guadaira, basado en el árabe rehat 'molino';

- Benagila;

- Benalosa;

- Benaborra: junto con los dos anteriores, nombre basado en antropónimo árabe (el nombre de los propietarios en la época del dominio musulmán);

- Marchenilla: posiblemente del hispanoárabe maŷšar o marŷy;

- Zacatín: posiblemente del árabe saqātīin $n^{5}$.

2. Al estrato anterior al árabe, esto es, al latino-mozárabe, remiten los topónimos que siguen:

${ }^{1}$ Véase Stefan Ruhstaller, «Interferencia lingǘstica en la Sevilla reconquistada: la TRADITIO NOMNUUM», en Actas del XX Congreso de la Sociedad Española de Lingüística, Madrid, Gredos, 1990, pp.
738-748.

${ }^{2}$ Véase Stefan Ruhstaller, «Cinco nombres de lugar testigos de la historia de Alcalá de Guadaira», en Actas de las IV Jornadas de Historia de Alcalá de Guadaira, Alcalá, 1991, s.v.
Sahela.

${ }^{3}$ Véase María Dolores Gordón Peral y Stefan Ruhstaller, El habla y la toponimia de Alcalá de Guadaira (en prensa), s. v. Marchamorón.

${ }^{4}$ Véase ibid., s.v. Marchenilla.

${ }^{5}$ Véase ibid., s.v. Zacatín. 
- Cortijena: nombre de una villa rústica romana, basado en el antropónimo latino CURTISIUS y el sufijo -ena de pertenencia ${ }^{6}$.

- Oromana: igual que el anterior ${ }^{7}$;

- Palmete: del lat. PALMÊTU 'palmar'8;

- Quintos: nombre del quinto miliar de una calzada romana';

- Cerraja: quizá fitotopónimo mozárabe ${ }^{10}$;

-Membrilla: mejor de un lat. MAMMULA 'elevación del terreno', con evolución mozárabe, que de un cast. membrilla 'planta'"1.

3. Nombres impuestos con anterioridad al estrato latino son:

- Gandul: basado en el prerromano GANDA 'pedregal' ${ }^{12}$;

- (Guad) aira: nombre no explicable ni a base del léxico árabe (falta el artículo árabe $a l$ tras $w a ̈ d \bar{l})$, ni por el latino ${ }^{13}$.

A estos nombres de los estratos árabe, latino-mozárabe y prerromano(s) cabe agregar aún los de Cajul y Otivar, cuyo origen resulta incierto, si bien está fuera de duda su no pertenencia al estrato castellano ${ }^{14}$.

Extraordinariamente interesante resulta ahora ver cómo los topónimos precastellanos analizados se distribuyen geográficamente por el área del término municipal de Alcalá. He confeccionado para este propósito el siguiente mapa:

"Véase Stefan Ruhstaller, "Cinco nombres...», art. cit., s.v.

${ }^{7}$ Véase María Dolores Gordón Peral y Stefan Ruhstaller, El habla, y la toponimia de Alcalá de Guadaira, op. cit., s.v. Oromana.

${ }^{8}$ Véase S. Ruhstaller, Toponimia de la región de Carmona, Sevilla, 1991, s.v. El Coronil.

${ }^{9}$ Véase ibid., s.v. Chiste.

${ }^{10}$ Véase El habla y la toponimia de Alcalá de Guadaira, s.v.

${ }^{11}$ Véase ibid., s.v., y Toponimia de la región de Carmona, s.v.

12 Véase Stefan Ruhstaller, "Cinco nombres...», S.v.

${ }^{13}$ Véase El habla y la toponimia de Alcalá de Guadaira, s.v. Guadaira.

${ }^{14}$ Véase ibid., s.vv. Otivar y Cajul. 


\section{Mapa: toponimia precastellana de la zona}

\section{de Alcalá de Guadaira}

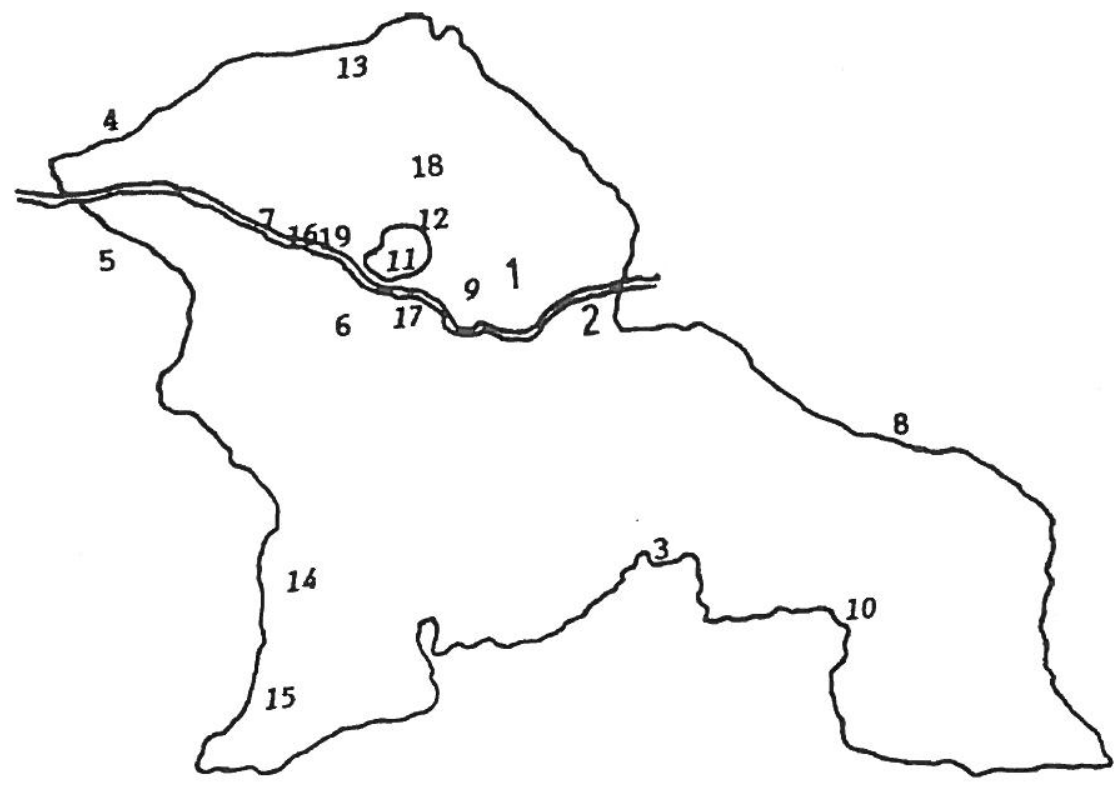

Nombres

prerromanos

1 Gandul

2 (Guad)aira

Nombres latinos
y mozárabes
3 Cortijena
4 Palmete
5 Quintos
6 Oromana
7 Cerraja
8 Membrilla

Nombres árabes

9 Marchenilla

10 Marchamorón

11 Alcalá

12 Zacatín

13 Sahela

14 Benaborra

15 Benagila

16 Realaje

17 Benalosa 
El mapa pone de manifiesto una acumulación de nombres precastellanos en las proximidades del área que hoy ocupa la localidad de Alcalá de Guadaira. Esta acumulación -como el hecho mismo de que se eligiese tal emplazamiento para asentamiento de la población desde antiguo, y de que el mismo lugar haya sido habitado desde tiempos prerromanos, sin interrupción, lo cual está garantizado por la perduración de numerosas denominaciones de origen árabe (Alcalá, Zacatín, Realaje, Marchenilla y Benalosa), latinas (Oromana, Cerraja), e incluso dos prerromanas (Gandul y el hidrónimo Guadaira)-, esta acumulación, decía, es explicable por constituir esta área una especie de encrucijada donde convergen dos zonas extraordinariamente favorables para un asentamiento humano perenne desde época muy temprana: Los Alcores y el Río Guadaira.

1) Los Alcores, en toda su longitud (hasta Carmona), constituyen un área de concentración de topónimos precastellanos, lo que se justifica por las excelentes condiciones estratégicas que brindaban estas elevaciones a la población ${ }^{15}$

2)A tales ventajas estratégicas se unían las económicas que suponía el antaño caudaloso Río Guadaira, que abastecía a la ciudad de agua, permitiendo el desarrollo de una economía centrada en la transformación del trigo y la aceituna. La secular importancia de los molinos en la economía local de Alcalá se refleja, precisamente, en la conservación hasta hoy de nombres de molinos de origen árabe (Realaje, Benalosa)y aun latino o mozárabe ( $\mathrm{Ce}$ rraja).

La pervivencia de un nombre en un sitio concreto es, como ya he dicho, un indicio clarísimo de que el sitio denominado ha estado poblado al menos desde la época en que fue bautizado. Es, pues, lógico deducir que, por ejemplo, en un sitio que lleva el nombre árabe de Realaje tiene que haber restos de un molino árabe; en un sitio nombrado Benaborra, restos de un asentamiento-quizá de una finca-de época árabe; en Oromana y Cortijena, vestigios de explotaciones agrícolas romanas etc., etc.

El testimonio de la toponimia puede ser aprovechado, pues, en la búsqueda arqueológica, constituyendo un instrumento de inestimable valor ${ }^{16}$ para realizar prospecciones sobre el terreno. Mas no debe olvidarse nunca que es de la interpretación linguística acertada de la que depende la probabilidad de detectar restos de interés arqueológico, por lo que es requisito indispensable para manejar la toponimia con garantías de éxito el disponer de formación especializada y utilizar un método lingüístico riguroso, y una base de datos lo más exhaustiva posible.

${ }^{15}$ Véase Toponimia de la región de Carmona, Capítulo 5.3.

${ }^{16}$ Versa sobre el tema del valor de la toponimia para la prospección arqueológica el extenso capítulo 3.17 de mi Toponimia de la Serranía de Sevilla. Estudio lingüístico e histórico, Sevilla, Universidad, 1990, así como mi trabajo «Del valor interdisciplinar de la investigación lingǘstica: Toponimia y Arqueología», en Actas del XX Congreso de la Sociedad Española de Lingüística, Madrid, Gredos, 1990, pp. 525-535. 


\section{B. Topónimos castellanos motivados por realidades de valor arqueológico}

Los nombres precastellanos no son los únicos datos toponomásticos aprovechables en la investigación arqueológica extensiva, aunque sí quizá los más conocidos entre los arqueólogos y los historiadores. Un segundo grupo de denominaciones de lugar suele aparecer con bastante más frecuencia y constituye una pista de una fidedignidad similar a la del primer grupo. Estoy refiriéndome a los nombres impuestos ya en el estrato actualmente vigente, el castellano, que contienen vocablos alusivos a hallazgos, por parte de los campesinos, de vestigios de culturas extinguidas ${ }^{17}$.

Nombres de este tipo abundan en prácticamente todo el territorio andaluz-si bien su frecuencia varía de área en área, conforme a la densidad de población en lo antiguo-, y también en nuestra zona de estudio hallamos algunos representantes. Entre éstos cuanta el topónimo Cortijo de las Tejas ${ }^{18}$. No puede caber duda de que las tejas a las que alude el nombre son en realidad vestigios dispersos (las llamadas tegulae por los arqueólogos) que permanecen de alguna construcción de época antigua y que atraen la atención del campesino, quien da en denominar al sitio según los llamativos restos. Que la motivación inicial no puede ser otra que ésta, nos queda asegurado por el testimonio de numerosísimos casos análogos; mencionemos, a título de ejemplo, los siguientes:

- Cortijo de Teja (término de Bujalance, Córdoba). Este sitio es descrito por el arqueólogo M. Ponsich como «vaste zone de fragments de briques et tuiles romaines mêlées à de la céramique commune et de la sigillée hispanique...»; - Casa de Teja (término de Montoro, Córdoba): «Ainsi est appelée une colline de forme allongée, sur laquelle on rencontre en surface de très nombreux fragments de briques et tuiles, céramiques commune»... ${ }^{19}$;

- Cortijo de la Tejera (Porcuna, Jaén), donde, según M. Ponsich, existe, «à l'Est du bâtiment, vaste zone de fragments de tuiles et briques romaines épars» ${ }^{20}$. - La Tejadilla (término de Cortegana, Huelva): «zona que, como su nombre indica, ofrece en superficie materiales de construcción y restos de cerámica», según J. M. Luzón'

- Tejada (Escacena, Huelva): impuesto ya en época romana, el nombre TEGULATA debía aludir a los restos de una población anterior en el lugar. J. M.

${ }^{17}$ Véanse aquí las obras citadas en la nota anterior.

${ }^{18}$ Forma ésta recogida en encuesta oral realizada a individuos naturales de la localidad de Alcalá de Guadaira, mayores de edad y buenos conocedores del término y sus nombres; en cambio, en el mapa del Servicio Geográfico del Ejército (hoja 13-41/49-31) y en el del Instituto Geográfico y Catastral de 1918 (hoja «Utrera»), figura la forma Cortijo de la Teja.

${ }^{19}$ M. Ponsich, L'implantation rurale antique sur le Bas Guadalquivir, Madrid, Publicaciones de la Casa de Velázquez, 1987, pp. 37 y 57.

${ }^{20}$ Ibid., p. 47.

${ }^{21}$ Véase AA.VV., Huelva. Prehistoria y Antigüedad, Madrid, Editora Nacional, 1975, p. 318. 
Luzón $^{22}$ asegura que «fuera de las murallas y en dirección a Patema hay restos de una construcción romana y se ven muchas tégulas. En el interior de la ciudad hay abundantísimas tejas romanas, «terra sigillata» e incluso cerámicas ibéricas pintadas»;

- La Teja (Carmona): M. Ponsich asegura haber hallado «fragments de tuiles épars, ainsi que de blocs de pierre taillée, dénotant une construction romaine» ${ }^{23}$.

Otro nombre surgido del estrato actual e indudablemente relacionado con la presencia, en el sitio denominado, de restos de interés para la Arqueología es el de Cerro del Moro ${ }^{24}$. En el caso del tipo toponímico basado en la voz moro, el nombre no hace alusión a un objeto concreto (como, por ejemplo, a te gulae; véase el topónimo anterior), sino a una leyenda popular de difusión local inspirada en vestigios, casi siempre abundantes y llamativos, que quedan de culturas extinguidas. Tales vestigios suelen dar lugar, por ser misteriosos e inexplicables para la población rústica, a la creación de leyendas muy parecidas en las más diversas localidades, y cuyo personaje principal es un ser fantástico de un tiempo antiguo indefinido, de quien se cuenta el haber habitado el lugar y dejado, en un sitio oculto, algún tesoro. Los nombres castellanos que delatan la existencia de restos arqueológicos no siempre hacen referencia, pues, a objetos determinados encontrados por los campesinos, sino a veces también a leyendas inspiradas en éstos. Como nombres de lugar análogos al alcalareño Cerro del Moro de otras áreas quiero señalar brevemente:

- Pozo Moro: es el nombre del lugar donde se han hallado las sepulturas monumentales más importantes de la Edad del Bronce Final y de la del Hierro en el área meridional ${ }^{25}$.

- Cueva del Moro y Castillarejo dels Moros son denominaciones de otros tantos yacimientos paleontológicos donde se han descubierto pinturas rupestres ${ }^{26}$.

- Sepultura del Moro es un topónimo de El Castillo de las Guardas (Sevilla) que hace referencia a un monumento dolménico del Neolítico ${ }^{27}$.

- Garrotal del Moro (Guillena, Sevilla): denominación de un extenso despoblado que presenta numerosos restos de época romana ${ }^{28}$.

- Cueva de la Mora (Jabugo, Huelva): importantísimo yacimiento de la Edad de Piedra, donde han aparecido útiles e interesantes grabados de la cultura magdaleniense ${ }^{29}$.

${ }^{22}$ Ibíd., p. 318. Véase también mi Toponimia de la Serranía de Sevilla, cit., s.v. Tejada.

${ }^{23}$ Véase S. Ruhstaller, Toponimia de la región de Carmona, s.v. Teja.

${ }^{24} \mathrm{He}$ recogido esta forma de las hojas catastrales y la he verificado en encuesta oral.

${ }^{25}$ Véase M. Almagro-Gorbea, «Pozo Moro. El monumento orientalizante, su contexto sociocultural y sus paralelos en la arquitectura funeraria ibérica», en Madrider Mitteilungen, 24 (1983), pp. 178-293.

${ }^{26}$ Véase M. D. Gordón, Toponimia de la Serranía de Sevilla, pp. 810 y 944.

${ }^{27}$ Ibid., s.v.Moro.

${ }^{28}$ Ibid.

${ }^{29}$ Véase Huelva. Prehistoria y Antigüedad, cit., p. 32. 
- Cabezo del Moro, también llamado Cerro del Ochavo, «lugar en el que la gente de Nerva busca monedas después de las lluvias» ${ }^{30}$.

Acerca de otro lugar menor de Alcalá refieren los autores del Catálogo Arqueológico y Artístico de la provincia de Sevilla:

«No hace apenas un siglo los restos de antiguas construcciones eran aún más numerosos. El P. Leandro J. de Flores, natural de Alcalá de Guadaira y cantor de sus glorias, cita restos de construcciones romanas en los lugares llamados Fuente de Benajila, Huerta de Medinilla, Otivar, Quiebrarrejas y otros» ${ }^{31}$.

La coincidencia del nombre Quiebrarrejas con la presencia de restos de interés arqueológico no puede ser casual. Esto queda patente a través de la comparación del nombre alcalareño con análogos de otras zonas, donde se da la misma circunstancia de haberse verificado descubrimientos de valor para la Arqueología:

-El primer elemento, Quiebra- (y también su equivalente Quebranta-) alude a lo dísperso y fragmentario de los restos antiguos con que se encuentran los campesinos en su labor agrícola. Así, los nombres Barranco de Quebrantabotijas (término de El Pedroso, Sevilla), Puerto de QuebrantaTinajas ${ }^{32}$,Quiebrapucheros o Quiebracántaros ${ }^{33}$ hacen referencia a trozos de recipientes antiguos desparramados por el suelo, y Quebrantahuesos ${ }^{34}$ y el sinónimo Cascahuesos $^{35}$, a restos óseos visibles en emplazamientos arqueológicos.

-El segundoelemento, -rejas, aparece también en el nombre de un lugarcarmonense donde se atestigua la existencia de vestigios de época romana: Pozo de la Reja ${ }^{36}$. La combinación con Quiebra- en el nombre de la estación arqueológica de Alcalá hace pensar que serían restos metálicos dispersos que a los campesinos, creadores de los nombres menores, les recordarían «rejas quebradas».

Un cuarto tipo de denominación de lugar del término de Alcalá que aparece dos veces y que muy seguramente hace referencia en ambos casos a una realidad de interés arqueológico es Piedra Hincada. Los lugares así bautizados se hallan en los extremos norte y sur del municipio, próximo el primero al límite con el de Mairena del Alcor, y el segundo a la linde con el de Utrera. No cabe duda de que estamos ante dos

\footnotetext{
${ }^{30}$ Véase ibíd., p. 316

${ }^{31}$ Véase J. Hemández Díaz, A. Sancho Corbacho y F. Collantes de Terán, Catálogo Arqueológico y Artístico de la provincia de Sevilla, Sevilla, 1965, t. I, p. 48.

${ }^{32}$ Véase Toponimia de la Serranía de Sevilla, s.vv. Botija y Tinaja.

${ }^{33}$ Véase Toponimia de la región de Carmona, s.v. Quebrantavigas.

${ }^{34}$ Véase AA.VV., Exploración Arqueo-Metalúrgica de Huelva, Río Tinto Minera S.A., Barcelona, 1981, pp. 101-114.

${ }^{35}$ Véase Toponimia de la Serranía de Sevilla, s.v. Hueso.

${ }^{36}$ Véase Catálogo Arqueológico..., t. II, p. 109.
} 
representantes del nutrido grupo de topónimos del tipo Piedra Hincada (o también Peña Hincada), cuya motivación inicial suele ser una piedra llamativa y de grandes dimensiones, clavada verticalmente en el suelo, y que a menudo remonta a una construcción de fecha inmemorial, comoun dolmen. Efectivamente, consta-por informes elaborados por arqueólogos-la existencia de monumentos megalíticos en los lugares denominados Peña Hincada de Gerena, Guillena, El Garrobo y Alcolea del Río ${ }^{37}$, Peñas Hincás de Zalamea la Real ${ }^{38}$ y Piedra Hincada de Utrera y Carmona ${ }^{39}$; en el caso de Piedra Hincada del término de El Coronil, parece que el topónimo hace alusión más bien a un monumento de época romana ${ }^{40}$.

Otro nombre, Las Canteras, alusivo a un sitio próximo a Gandul, constituye por símismo una pista para la exploración arqueológica. En efecto, el tipo Cantera $(s)$ señala en la toponimia hispánica lugares con restos de edificaciones antiguas o explotaciones de donde se extraía la piedra necesaria para la construcción en tiempos pasados, y, señaladamente, ya desde época prehistórica. Pero de este caso concreto conocemos de hecho la referencia inicial, pues, como bien ha indicado el arqueólogo F. Amores ${ }^{41}$, estas canteras han sido explotadas desde época romana, extrayéndose sillares seguramente para abastecer al vecino establecimiento de la Mesa de Gandul. Otros lugares bautizados con esta misma forma Cantera (o con el aumentativo Canterón), de los que igualmente consta la motivación inicial, de enorme interés arqueológico, son:

- Las Canteras (Guillena, Sevilla): nombre de un lugar es donde se halla un megalito que los historiadores colocan cronológicamente en la Edad del Bronce; - Las Canteras (Gerena, Sevilla): denominación de otro extenso despoblado de época prehistórica ${ }^{42}$;

- Los Canterones (Estepa, Sevilla): nombre de un despoblado que, a juicio de los historiadores, ya estuvo habitado en época tartesia. El topónimo se explica-dicen los autores del Catálogo Arqueológico Provincial de Sevilla-por «haber servido de antiguo el lugar para extraer piedra de construcción, habiendo quedado bien visibles las huellas de tales extracciones, tanto en profundas excavaciones como en trabajos superficiales, que muestran en algunos sitios los sillares a medio cortar [...]. No parece desprovista de fundamento la opinión de Aguilar Cano de que el despoblado romano de los Canterones hubiese estado constituido por los restos de las viviendas y talleres de los operarios que explotaban la piedra en aquellas canteras» ${ }^{43}$.

\footnotetext{
${ }^{37}$ Véase Toponimia de la Serranía de Sevilla, s.v. Peña.

${ }^{38}$ Véase Huelva. Prehistoria y Antigüedad, p. 97.

${ }^{39}$ Véase Toponimia de la región de Carmona, s.v. Piedra.

${ }^{40}$ Véase ibíd.

${ }^{41}$ F. Amores Carredano, Carta arqueológica de Los Alcores (Sevilla), Sevilla, 1982, pp. 151, 152 y 181.

${ }^{42}$ Véase Toponimia de la Serranía de Sevilla, s.v. Cantera.

${ }^{43}$ Véase Catálogo Arqueológico..., t. IV, p. 29.
} 
Porotra parte, el nombre alcalareño ElBaño ${ }^{44}$ nos recuerda los numerosos topónimos Baño(s), Bañuelo(s) y semejantes, que se dan por todo el territorio hispánico, aludiendo por regla general a construcciones antiguas. Cabe mencionar los siguientes casos:

- Huerta del Bañuelo de Guillena, que «hace indudable alusión a la existencia en aquel sitio de construcciones hidráulicas conocidas desde antiguo» ${ }^{45}$;

- También contamos con referencia documental de un lugar llamado Los Bañuelos del término sevillano de Coria del Río, citado en texto de $1495^{46}$. -Pero mucho más antiguas son las atestiguaciones del topónimo Los Bañuelos de Écija, que remontan a mediados del XIII. En el Libro del Repartimiento de dicha ciudad, de 1263, se hace alusión a una aldea de Bañuelos; se trata seguramente de uno de los muchos núcleos de población abandonados y arruinados ya desde antes de la Reconquista ${ }^{47}$.

- Al Cortijo de los Bañuelos de Estepa se refieren los autores del Catálogo Arqueológico, que comentan: «Su nombre puede provenir de haberse hallado allí en algún tiempo piscinas o depósitos de agua romanos. Está situado al pie de Los Canterones, cercano a la carretera de Écija, encontrándose en él bastantes fragmentos de cerámica basta, pertenecientes a grandes recipientes y otras vasijas de uso casero ${ }^{48}$.

- En el Rancho Los Bañaderos del término gaditano de Arcos de la Frontera existen restos abundantes de depósitos hidráulicos de época romana ${ }^{49}$.

- En La Bañita, lugar del Coto de la Mora, en el término onubense de Almonaster, se hallan numerosas fosas excavadas en la roca, que los historiadores fechan en época prehistórica ${ }^{50}$.

- Baño de la Reina Mora se llaman los restos que permanecen de la ciudad romana de SALPENSA, en término de Utrera ${ }^{51}$; la Reina Mora que menciona el nombre debe hacer alusión a un ser fantástico, personaje de una leyenda local inspirada en los vestigios del yacimiento arqueológico (compárese el caso similar de Cerro del Moro, estudiado supra). Análogos son los casos de Baños de la Reina de Celín (Almería) y Baño de la Reina (Alhama de Granada), nombres que corresponden a sitios con abundantes restos arqueológi$\cos ^{52}$.

Las Canteras.

${ }^{45}$ Véase Toponimia de la Serranía de Sevilla, s. v. Bañuelo.

${ }^{46}$ Ibid.

${ }^{47}$ Véase Catálogo Arqueológico..., t. IV, p. 23.

${ }^{48}$ Ibíd., p. 39.

${ }^{49}$ Véase Toponimia de la Serranía de Sevilla, s.v. Bañuelo.

${ }^{50}$ Véase Huelva. Prehistoria y Antigüedad, p. 170.

${ }^{51}$ Véase Toponimia de la región de Carmona, s. v. Fazalcázar.

${ }^{52}$ Boletín del Instituto de Estudios Almerienses, Excma. Diputación, Almería, 1982, pp. 109 y 112. 
También el nombre de lugar El Toruño llama la atención del toponimista. El vocablo toruño, que constituye la base del topónimo, ha sido apelativo castellano vivo hasta época reciente, con valor de 'elevación pequeña y redondeada del terreno' (muchas veces la formada por un túmulo o un dolmen) ${ }^{53}$. La probabilidad de que el nombre de Alcalá esté inspirado en la existencia in situ de un monumento prehistórico se ve acrecentada por el hecho de que El Toruño es un lugar ubicado en un vértice de Los Alcores, en las proximidades de la estación arqueológica de Gandul (para el interés arqueológico de la comarca de Los Alcores, y concretamente de Gandul, vid. supra). $\mathrm{He}$ demostrado en mi Toponimia de la Serranía de Sevilla que tienen, en efecto, una motivación inicial de sumo interés para la investigación arqueológica muchísimos nombres del mismo tipo que el alcalareño, El Toruñ $o^{54}$; son perfectamente equiparables -tanto etimológica como referencialmente- las numerosas variantes Torroñal, Turruñuela, Tur(r)uñuelo,Toruñuelo,Torruño,Toroño, Toraño, Toroñedo, Terrón, Torón, Turullote, Troya, Torrilla, etc., etc.

Un segundo tipo oronímico de evidentes connotaciones de valor para la Arqueología es el de Camorra, del que hallamos un representante en elárea de Alcalá ${ }^{55}$. Lo mismo que en el caso anterior, el lugar denominado Camorra es una de las elevaciones de Los Alcores. En vista de que a menudo existe una innegable relación entre topónimos de este tipo en otras áreas hispánicas y las características de los lugares, que ofrecen indicios de habitación humana de época primitiva, no resulta descaminado conjeturar la existencia de restos de interés arqueológico también en el sitio alcalareño de La Camorra, si bien resulta menos seguro que en los casos anteriormente analizados.

Finalmente, uno de los nombres de lugar mencionados más arriba, La Membrilla - Cerro de la Membrilla, quizá deba considerarse, como los dos inmediatamente precedentes, otro representante de un tipo oronímico interesante por su elocuencia para la detección de yacimientos de valor para la Arqueología. En efecto, tal topónimo debe remitir a una originaria formación diminutiva MAMMULA+ELLA, con referencia claramente oronímica, esto es, motivada por la pequeña y redondeada elevación del terreno que sería aprovechada desde antiguo como asentamiento por los pobladores de esta zona. Dos hechos vienen a apoyar esta interpretación del nombre:

a) el nombre de Alcalá aparece documentado como La Membriella o La Menbriella ya en el Repartimiento de Sevilla, hecho que permite suponer que el nombre en cuestión fue heredado por los árabes de los mozárabes del lugar, quienes lo impondrían -adviértase que la forma presenta una característica evolución dialectal mozárabe-. De labios árabes habrían de tomarlo a su vez los repobladores castellanos, autores del Repartimiento de Sevilla.

\footnotetext{
${ }^{53}$ Véase Toponimia de la Serrania de Sevilla, s.v. Turruñuela.
}

${ }^{54}$ Véase ibíd. El sitio El Toruño se localiza en el mapa del Servicio Geográfico del Ejército en las coordinadas 13-40/54-36. También he recogido el nombre en encuesta oral.

${ }^{55}$ Forma recogida en encuesta oral. Figura también en el mapa del Instituto Geográfico y Catastral de 1918, en la forma Vereda de la Camorra (véase la hoja «Utrera»). 
b) A la transmisión del nombre de un estrato a otro, significativa de la permanencia continuada de población en el lugar, viene a sumarse el hecho conocido de la existencia de construcciones in situ, una de las cuales se cita en documentos antiguos como Torre de la Membrilla.

Y para terminar, ciertos nombres de lugar de Alcalá pertenecen a la tipología de denominaciones que constituyen pistas para la prospección arqueológica: Almenara, Las Almenas, La Torrecilla, Torrepalma, Torre San Josés6. En Toponimia de la Serranía de Sevilla estudio numerosos topónimos con formas idénticas o muy similares, correspondientes todos ellos a lugares de interés arqueológico ${ }^{57}$; los sitios alcalareños mencionados merecerían, pues, un examen minucioso por parte de expertos.

${ }^{56}$ He podido comprobar la vitalidad de estos nombres en el habla local a través de encuestas orales.

${ }^{57}$ Véase Toponimia de la Serranía de Sevilla, apartado 3. 17. 